\title{
Semiotic Threshold: Animals and People
}

\author{
Irina B. Ptitsyna \\ Independent Researcher (ptiirina@yandex.ru)
}

Received: December 2020 Accepted: April 2021

\begin{abstract}
The author discusses the question of whether animals have a language. The article examines the similarities and differences in the linguistic capabilities of animals and humans. The similarity lies in the fact that animals can use symbolic signs to receive and send messages. Among other things, they can receive and interpret signs on a delayed basis without the direct presence of their sender, although to a fundamentally lesser extent than people. The comparison is carried out both for signs perceived by the organism (afferent signs) and for signs created by the organism (efferent signs), both related to communication and the perception of the environment outside the community.

The main difference is the possibility of telling about events outside the "here and now" in which the narrator could or may not take part. This is the narrative. No signs of animals using the narrative were found. The resulting differences in storytelling use are hypothesized to be related to additional language functions that have increased in humans compared to animals. People have psychological characteristics caused by the presence of the stage of individuation and separation in development. This allows them to move away from the situation and see it from the outside, which is necessary for retelling. On the other hand, people need to communicate with the help of a narrative, since their society includes a sacred part, whose members receive descriptions of events, requests, questions, and their answers in the form of various signs and the results fortune-telling need a detailed interpretation.
\end{abstract}

Keywords: language, semiotic threshold, sense, sign-symbol, afferent sign, efferent sign, narrative, individuation and separation, sacral.

There is a widespread belief that the basis of the human language is the linguistic behaviour of animals-those animals that were the ancestors of humans. The emergence of human language is traced back to different periods of the formation of Homo sapiens, and now there is even an theory that not only Homo sapiens, but also Neanderthals possessed such a language (Dediu, Levinson 2018). There is a hypothesis that the Heidelberg man already had language (Mithen 2005). Of course, learning the language of a long-extinct species is a very, very problematic matter, therefore, they usually rely on knowledge about forms of knowing (Kull 2014) (more often called a language with reservations-"language," animal language, proto-language or semiosis, communication, communication system) those animals that exist now.
Historically, the term "language" was used in linguistics and referred specifically to human language. It is believed that speaking about language or something similar in relation to animals is possible only if one adheres to an anthropomorphic point of view (Wendler 2020). However, it is obvious that there is a phenomenon that resembles the language of humans and performs similar functions, which is best studied by biosemiotics as a manifestation of semiosis (Kull 2014). The question is of how humans and other animals differ in this is linked to the question of how humans and animals differ in total, and what a person is in general.

For a long time, animals have been denied that they have language, at best admitting that they have communication since they cannot communicate the way 
humans can-ask or discuss something (Sebeok 1990; Kull 2010, 2014; Maran et al. 2016; Hockett 1960; Cheney and Seyfarth 1998). There is another opinion-the presence of language was recognized for animals (Savage-Rumbaugh; Rumbaugh, Fields, 2009; Burlak 2013; Cimatti 2016; Reznikova 2017; Delahaye 2018). The change of opinion is because, if earlier they relied on the criteria of differences associated with the structure of human language, then later they began to emphasize the similarity based on the role that language plays in the life of the community. Because the very concept of language in animals is not clearly defined, a large amount of scattered literature has appeared on the topic of the similarities and differences of these languages (Kull 2009; Taylor 2016; Costa 2017; etc.). It is necessary to understand what is the difference between the language of animals and humans, and why they differ.

The very formulation of the question of these differences is not so simple. A clear boundary can be drawn when objective parameters that can be reliably measured are studied. For example, the aggregate sets of human and animal genomes will be clearly different in some part. The question of the difference in languages or methods of communication is subjective and, like any opinions, it does not have a clear border, and obvious differences are visible only in the main part of the aggregate opinions, which can intersect with their edges. Besides, different researchers can put different meanings in the same terms, making it difficult to analyse and understand the big picture.

\section{EXPLANATIONS}

There are several similar but different concepts. These are sign systems, language, communication, speech, sign, word. Artifacts and cultural objects are very closely connected with them. Various authors put in these concepts a similar, but not always quite the same meaning. For clarity of the presented text, I will first explain how I understand these terms.

A sign is a mental image of a sign-vehicle, endowed with a sense, its own or partially overlapping with the meanings of other signs. The sign arises when sense arises, when the sensory image and the image of the corresponding need coincide. The sign of the sensory image of some part of the external environment (which can be perceived by sensory systems) is an afferent sign. The coincidence of the image of the motor reaction of the body scheme or other activity and the image of the need gives sense to the efferent sign. The specific sense is always individual. Sensory images and images of needs are not symmetrical, as motor images and images of needs. Signs are both natural and artificially created with special intention (artifacts).

Sign system (individual) for animals coincides with the Umwelt as a signified and mastered part of the external world. For people, the sign system includes not only signs related to the material part of the external world, but also signs attributed by people to various elements and phenomena of this world. They become the basis, content, respectively, of individual, general, and abstract concepts.

Communication is a concrete implementation of the transfer of a message from the sender to the recipient. The transmission can be done using words and/or signs. The participation of at least two interlocutors is mandatory, while the addressee's participation may be delayed. Messages can be implemented in the form of a monologue and or a di-polylogue.

Word is the name of the sign, the sign of the sign, it refers to the signs-symbols, but it has that peculiarity in humans, in contrast to the signs-symbols of animals, which refer not only to specific objects and phenomena but also to generalized and abstract concepts. Not all signs have names. Words can be presented in various grammatical forms, reflecting both their relationship to each other in a phrase and the relationship between the elements of reality that they denote. Words are the basis of a narrative.

The language of people is a complex multidimensional education: an open system. It includes external manifestations related to communication (oral and written speech, sending and receiving messages) and internal manifestations (internal speech and the process of generation and understanding, interpretation of speech when compared with accumulated experience). It can be viewed from different sides as a mental process, as a psychological phenomenon and from the side of physical properties-muscular actions during internal and external speech. The process of generating and understanding speech is thought.

The language of animals, each species has its own-is also an open system. It can be replenished with learning but to a limited extent. The languages of animals can be spoken of as conventions or metaphors: "language" or the "language of animals." The human language and the "languages" of animals differ greatly not only in quantitative characteristics but also qualitatively in composition and functions. It cannot be said that the "language of animals" is worse or poorer than the language of humans since it fully performs its functions. There are many examples of particular differences, but this does not give a complete answer to the question of how these languages differ. The answer can be found in how the problems solved with the help of the language differ.

\section{CRITERIA FOR DISTINCTION}

The language of humans is distinctly different from the "languages" of animals in that:

- People use not only oral but also written speech. For written speech, specialized artifacts are used. The essential difference lies in the conditions, reasons for the appearance, and tasks that are assigned to writing. 
- The presence of artifacts as objects endowed with meaning, i.e., specially made signs, made on different physical carriers, which have no pragmatic meaning per se. They are now classified as cultural phenomena-painting, sculpture, music, ballet, etc. This also includes equipment and various devices for scientific research and training. They are also adjoined by cult objects-talismans, amulets, icons, and so on. Written speech is a type of specialized artifact.

- The use of a narrative, that is, the presence of grammar in the language that will allow the transmission of messages not only related to the reporting person at the moment but also to other situations in which the narrator does not participate.

The criteria of distinction are the presence of 1) signs-symbols (symbol) which owe their existence to a social contract and in which the signified has no direct relation to the signifier; 2) the possibility of delayed receipt of the sign without the direct presence of the sender (the function of the letter) and; 3 ) the possibility of signs, often their combination, to communicate something that is not related to the current situation of the sender, or even to transmit a message that is not about them.

There are other less noticeable differences.

In biosemiotics, this question is considered the definition of the upper semiotic threshold (Kull 2009).

The point of view that admits the possibility of the presence of language in animals is based on other grounds. An overview of such opportunities is given by $D$. Martinelli (2010). First of all, such a possibility allows adherence to anthropocentrism. H. Wendler, (2020) and F., Jaroš, \& T. Maran, (2019) are considering this possibility. But $H$. Wendler himself does not use the term language here and leaves the question open literally:

I do not know what to speak thereof. And, therefore, I shall be silent (2020: 80).

Sometimes ethologists accept the point of view of the presence of language in animals. For example, the word language is used by A. Burlak (2013). But, since she uses the word communication as a synonym, one might think that this is not a term, but only a metaphor.

\section{SIGNS}

If we consider the situation from the point of view of the methodology of biosemiotics, then we should, first of all, pay attention to the differences and similarities of signs used by humans and animals.

Charles Peirce divided signs into three categories symbolic, indexical, iconic (Peirce 2000) and the adherence to such a division continues to this day (Frohlich 2014, Favareau 2015 and many others). It is not always easy to draw clear lines between the signs of these three categories. Each group contains a collection of somewhat similar but different signs. New types of signs are also being considered (Kull 2018, 2019).

Signs-indexes. Here are collected signs and those that directly indicate the object and those that indicate the sign-vehicles associated with the designated object or phenomenon. For example, smoke as a sign-vehicle can be the source of the smoke sign itself and the fire sign if the smoke is a result of burning.

Iconic signs correspond to the sign-vehicles in the form of any image, drawing, or diagram embodied in various materials and mean the depicted object. Such a sign-carrier is an artefact, is a fact of culture, but not related to written and oral speech.

Signs-symbols, denoting an object based on the convention. A sign-vehicle can be an element of speech, either a written one using pictorial, hieroglyphic, alphabetic, nodular, and other types of writing, as well as an oral: vocal and language of gestures. It is believed that this type of sign is characteristic only of the human language (Kull 2014). However, there is another opinion (Hoffmeyer 2008; Jaroš, Pudil 2020) that animals also use symbols discussed in this article. Below is a discussion of learning in society as a prerequisite for mastering these signs.

Such a classification as a logical structure based on the results of interpretation is convenient for the subject and belongs to semiotics. It allows you to order signs on the basis of the relationship between the signified and the signifier. The index sign refers to a real object directly or referring to an object functionally related to it; the icon sign refers to an object through its image; the symbol refers to an object indirectly through a specially created other object in its characteristics that has no connection with the designated one, the connection with which is established as a result of special training or convention. Those from the point of view of semiotics, people have all three types of signs, and animals have only the first two. Following this logic, one would have to admit that animals do not have language, but use other sign systems. In addition, it should be noted that this classification applies to both perceived afferent and created efferent signs.

However, biosemiotics, like zoosemiotics, considers not only the result but also the process of the formation of a sign.

Afferent signs formed based on perceptual images of the external world in animals are of all types discussed above. We can say that Peirce's classification considers this type of signs since it is focused on the perception of signs by an outside observer.

The same element of the external environment can be the source of different signs. Much in the perception of the image of the sign-vehicles depends on the choice of perceived parameters and on the interpretation. You can recall the well-known parable of the blind men and the elephant, where every blind man thought that the elephant was that part that he felt. Also, for example, a drawing of a cup can be perceived as a sign of a cup, a drawing of a flower in its decor as a sign of a flower, colours of 
decor as signs of each colour, the drawing itself as a sign of a sheet of paper, etc. This, to varying degrees, applies to all types of afferent signs.

All the signs, except congenital ones, require learning.

A proto-sign refers to congenital signs. They were introduced by G. Prodi (Kull 2018) as an element of protosemiosis. Let's leave aside the question of the semiosis of non-living systems and accept that proto-signs are characteristic of the lowest level of organization of living things: immune reactions, genetic code, and the cellular level. Here, apparently, it is possible to add congenital unconditioned reflexes in animals with a nervous system, which are especially characteristic of newborns and very young individuals, and with age, they appear only in special situations. These congenital signs, as well as the reaction to them, constitute the basic set of the innate minimal Umwelt.

Learning signs-indices is the simplest and corresponds to self-learning during the formation of natural reflexes or imitation. Signs icons and symbols require special training. Visual and diverse examples of learning can be conditioned reflexes, where a signal can be any element of the external environment not related to the properties of the sign-vehicle. For example, for the food-conditioned reflex, the blinking of a light bulb, the sound of a certain tone, and even painful irritation were used as a sign of food. It should be noted that the procedure for developing a conditioned reflex is a kind of communication between the experimenter and the experimental animal. Symbols are used not only by vertebrates but also by insects with a complex social organization (i.e., the language of bees). In this way, the condition for the perception of symbols by animals is fulfilled for efferent signs.

Efferent signs formed based on images of needs from the inner world are externally expressed in activities or functions. This is the work of the secretory glands and muscles. Muscles support posture and balance and provide movement of the body and its parts, as well as the muscles of the vocal apparatus that produce sounds

Here it is necessary to distinguish signs by who is the interpreter of these signs-the sender himself or the recipient (Morris 1955[1946]).

Perception by the addressee. Perceptive signs are of a dual nature. They are efferent in origin and afferent in perception.

The external appearance, posture, movement, everything can be perceived by another organism as signs from the external environment, indicating the existence of an organism of its own or of another type. The signs can be classified as proto-signs and index signs. It is believed that the expression of emotions in the elements of behaviour is innate. Among them, there are simple signs, such as screams of fear when a predator appears, which is perceived by relatives as a signal to flee. But, an increase in the repertoire of such screams, for example, by which they distinguish whether an attack from the air or from the ground means that an agreement has been reached on new signs as a result of training. These signs are produced specifically to convey a message. They can be attributed to the signs-symbols that make up communication or language.

It is known from numerous works of ethologists that animals teach their young to hunt. Social contact training is not so obvious to the observer. The fact that people should be brought up in society is obvious from the examples of "Mowgli," those children who were brought up by animals. Studies of the behaviour of animals raised in conditions of social isolation (Shabanov, Lebedev 2007) show that animals should also socialize in their community. Behaviour in society is regulated by the establishment of rank and other systems of relations, rituals, communication, i.e. using sign systems. It is known that experimentally isolated animals cannot behave, let alone communicate, adequately. Male rats become aggressive and perceive any contact as an attack to which they respond with aggression, and female rats become excessively obtrusively sociable. In other words, an innate understanding of signs or based on their own individual experience is not enough for full communication. It should be recognized that in this manifestation of communication, an agreement on the meaning of signs in the learning process is necessary. As a result, it becomes possible to perceive signs-symbols, and according to this criterion, the manifestation of communication can be considered a language.

Perception of the addressee's own signs. The situation is somewhat different when efferent signals are interpreted by senders.

All parameters and manifestations of appearance that are not specially intended to convey a message are signs in the event that they contribute to the satisfaction of any need. Then the image of movement, the scheme of the body, acquire the sense of sense and, accordingly, become signs if they link with the need caused that them. These are proto-signs and index signs.

The bodily (manifestation of posture, vocalization) expression of emotion belongs to the type of signs described by Kalevi Kull as emons (Kull 2019) and can be used for communication. Emotions, as an innate involuntary reaction, arise when needs are unfulfilled. Expanding the proposed concept of the emon, it can be argued that the arbitrary expression of emotions requires socialization and training and corresponds to signs-symbols. Emons can denote the entire spectrum of elements of social behaviour in animals and are included in human language as paralinguistic elements. In the same way, as for afferent signs, the same element of reality can be perceived as several sign-carriers. This can be illustrated by the parable of the three stonecutters. They were asked what they were doing. The first one answered, "Making money." The second one said, "I am chopping a stone." And the third said, "I am building a temple."

The signs used for communication are often symbols that meet one of the criteria of the language. However, they are expressed through posture or vocalization, 
which does not allow them to be perceived in a delayed manner. Delayed perception is the second criterion of language is also found in animals, but rare cases. Examples are the scent marks that wolves and dogs leave to mark the boundaries of their territory. These are scent marks made from sweet aphid syrup that ants use to mark their way to their pets. Probably, these two criteria can be considered as evidence of the presence in animals of some semblance of language, obviously with fewer possibilities than human.

\section{NARRATIVE AS THE THIRD CRITERION.}

In his works, Daniel D. Hutto $(2009,2009)$ also adheres to the opinion of the presence of a narrative as a criterion for a full-fledged language. However, there is only a mention of the origin of the narrative that it is associated with the emergence of faith as an instrument of worship. I believe that this point of view may apply to modern secularized society, but not to archaic. The need only to honour the gods, as well as otherworldly entities, cannot be a sufficient reason for such a powerful development of the inclinations of language into a human language. The question is much more complicated and deeper.

It is difficult to judge narrative in animals as statements about something unrelated to a given situation. The perception of emons can be easily judged by the behaviour of the listeners. The narrative does not necessarily evoke an immediate response, but for the most part, modulates further actions. The story is always carried out in the word-spoken or written. A word is a sign of signs, it is not just a symbol, but a specially created artificial symbol. We assume that there is no narrative in animals, relying on some differences in the psychological development of animals and humans and differences in their social communities.

Small children in their psychological development, starting from about one year of age, go through the stages of separating themself from the environment (individualization) and separating familiar objects from their environment (separation) (Mahler et al. 1975). Animals in their idea of the world around them remain merged with it. This leads to several consequences of which we note two:

- the sign-symbol in animals denotes the whole situation as a whole, without highlighting its parts. For example, a warning cry in case of danger at the same time indicates the emotion of the watchman about the type of danger and about the behaviour to which it calls for (to run away or hide). With this cohesion, there is no grammar required for a narrative.

- This fusion does not allow animals to move away from the situation and see it from the outside, which is necessary for retelling. In the life of animals, there is no need for a story about the history of any events, since there is no need for such a retelling (Cheney, Seyfarth 1998). The animal society is structured in such a way that its interested members are sufficiently informed and participate in the events taking place (Cheney, Seyfarth 1998).

Human society is structured differently. It becomes necessary to send messages to those who did not participate in the events. In addition to that part of it, which is arranged in accordance with the animal nature of man, there is another part that is not so obvious for the modern man. The history of human development is divided into several stages. Starting from the first stage, the phase of animism in people of the archaic period, a sacred part of society is added, which consists of animate nature and later of the gods. People need to communicate with this part of society. The former part can be considered as profane (material) and the new one as sacred (the ideal world of spirits, souls, and the like). Apparently, both of these parts were not initially perceived separately from each other. The emergence of the sacred initiates the development of sign systems-those that are subsequently viewed as cultural phenomena: art, music, dance, and others among which the most important is the development of language. Sign systems provide communication through rituals and other new ways and new possibilities. As one of the most important, complex communication arises with the help of a narrative, since the members of this part do not participate in current events like the profane part, but act willfully. The profane part tries to establish the necessary contact and turn to the descriptions of events, requests, questions, and sacred part answers in the form of various signs and results of fortune-telling need a detailed interpretation. This is precisely the boundary, the semiotic threshold, which fundamentally distinguishes between the languages of animals and humans.

\section{CONCLUSIONS}

When comparing the linguistic behaviour of humans and animals, it can be noted that those methods of communication that are recognized for animals are to one degree or another present in the human language and they can be considered as a transformed inheritance from the period when the ancestors of humans did not yet possess the language. These are 1) gestures, mimicry of voice intonation-what is commonly called paralinguistic elements of language and; 2) linguistic elements such as interjections and other ways of expressing emotions.

In animals, it is inappropriate to call such linguistic manifestations language. The term is already in use and is used for human language. In addition, the linguistic behaviour of animals does not meet all the criteria proposed in the article. However, this phenomenon in animals fully satisfies communication needs, therefore it cannot be considered as a truncated part of the human language. This is not semiosis, because semiosis is more than language. This is not communication, either, since communication is only an external manifested part of the language without taking into account the internal processes of understanding or interpreting a message 
and preparing it for transmission. Phenomena such as "communication," "message transmission," "communication with the help of sign systems" are present in both animals and humans, and they have differences and similarities similar to those in the language.

Of the three criteria for the existence of language considered here, two are insufficient to assert the presence of language in animals. The point of view is offered that one can speak about language in animals only conditionally. For example, you can speak as a "language" (in quotes) or as the language of animals (with the obligatory addition-animals) or, a proto-language. Therefore, the author believes that animals do not have a "language" but have a "language of animals."

\section{ACKNOWLEDGEMENTS}

I am very grateful to Sergei Krylov and Nonna Otmakhova for discussion to this manuscript.

\section{REFERENCES}

Burlak, A.,2013. Languages, DNA, relationship and contacts. Journal of Language Relationship: International Scientific Periodical, 9, 55-67, available at: <https://www.academia.edu/20060833/ Languages_DNA_relationship_and_contacts>

Cheney, D. L., Seyfarth R. M., 1998. Why Animals Don't Have Language. In G. B. Peason (Ed.), The Tanner lectures on human values, Salt Like Sity, UT: University of Utah Press. 174-209., available at:

<https://www.researchgate.net/publication/251885739_Why_Animals_Don“t_Have_Language/ citations>

Cimatti, F., 2016. Wittgenstein on animal (human and non-human) languages. Linguistic and Philosophical Investigations, 15, 42-59, ISSN 1841-2394, available at: <https://www.academia.edu/29338788/WITTGENSTEIN_ON_ANIMAL_HUMAN_AND_NON_HUMAN_ LANGUAGES>

Costa, P., 2017. The Language Animal: A Long Trajectory. Dialogue 56(4), 621-632, available at: <https://doi.org/10.1017/S0012217317000774, https://www.academia.edu/35736726/ The_Language_Animal_A_Long_Trajectory?sm=a>

Dediu, D., Levinson, S. C., 2018. Neanderthal language revisited: not only us. Current Opinion in Behavioral Sciences, 21, 49-55, available at: <https://doi.org/10.1016/j.cobeha.2018.01.001>,<https://scinapse. io/papers/2793163934>

Delahaye, P., 2018. Zoosemiotics 2.0. International Journal for the Semiotics of Law, Revue Internationale de Sémiotique Juridique, 31(3), 707-714, available at: <https://doi.org/10.1007/s11196-0189563-z>, <https://link.springer.com/article/10.1007/ s11196-018-9563-z\#>

Favareau, D., 2015. Symbols are Grounded not in Things, but in Scaffolded Relations and their Semiotic
Constraints (Or How the Referential Generality of Symbol Scaffolding Grows Minds. Biosemiotics, 8(2), 235-255.

Frohlich, D. R., 2014. Biology, Peirce, and Biosemiotics: Commentaires 'Cénoscopic' d'unBiologiste. The American Journal of Semiotics, 30(1-2), 173-188, available at: <https://www.academia.edu/21315696/ Biology_Peirce_and_Biosemiotics>

Hockett, C. F., 1960. Logical considerations in the study of animal communication. In Lanyon, W. E.; Tavolga, W. N. (Eds.), Animals sounds and animal communication. American Institute of Biological Sciences, 392-430.

Hoffmeyer, J., 2008. Biosemiotics: An examination into the signs of life and the life of signs. Scranton: University of Scranton Press.

Hutto, D. D., 2009. ToM Rules, but It Is Not OK. In: Leudar I., Costall A. (eds) Against Theory of Mind. London. Palgrave Macmillan, pp. 221-238.

Hutto, D. D., 2009. Folk Psychology as Narrative Practice. Journal of Consciousness Studies, 16(6-8), 9-39.

Jaroš, F., Maran, T., 2019. Humans on top, humans among the other animals: Narratives of anthropological difference. Biosemiotics, 12(3), 381-403, available at: $<$ https://www.academia.edu/40712011/Humans_on_ Top_Humans_among_the_Other_Animals_Narratives_ of_Anthropological_Difference>

Jaroš, F., Pudil, M., 2020. Cognitive Systems of Human and Non-human Animals: At the Crossroads of Phenomenology, Ethology and Biosemiotics. Biosemiotics 13(2), 155-177, available at: <https://www. researchgate.net/publication/342337131_Cognitive_ Systems_of_Human_and_Non-human_Animals_At_ the_Crossroads_of_Phenomenology_Ethology_and_ Biosemiotics>

Kull, K., 2009. Vegetative, Animal, and Cultural Semiosis: The semiotic threshold zones. Cognitive Semiotics, 4 (Spring), 8-27. available at: <https://www.academia.edu/220345/Vegetative_animal_and_cultural_ semiosis_The_semiotic_threshold_zones>

Kull, K., 2010. Umwelt and modelling. In P. Cobley (Ed.), The Routledge companion to semiotics (pp. 43-56). London, New York: Routledge>

Kull, K., 2014. Zoosemiotics is the study of animal forms of knowing. Semiotica, 2014(198), 299-310, available at: <https://www.academia.edu/6116777/Zoosemiotics_is_the_study_of_animal_forms_of_knowing>

Kull, K., 2018. Biosemiotics by Giorgio Prodi: A postscript. In: Cimatti, Felice, A Biosemiotic Ontology: The Philosophy of Giorgio Prodi. (Biosemiotics 18.), Berlin: Springer, 135-147, available at: <https://doi.org/10.1007/978-3319-97903-8 https://www.academia.edu/37955881/ Biosemiotics_by_Giorgio_Prodi_A_Postscript>

Kull, K., 2019. Steps towards the natural meronomy and taxonomy of semiosis: Emon between index and symbol? Sign Systems Studies 47(1/2), 88-104, available at: <https://doi.org/10.12697/SSS.2019.47.12.03 https://www.academia.edu/39765119/ 
Steps_towards_the_natural_meronomy_and_taxonomy_ of_semiosis_Emon_between_index_and_symbol>

Mahler, M. S., Pine, F., Bergman, A., 1975. The psychological birth of the human infant. Symbiosis and individuation. New York: Basic Booka, Inc., Publishers.

Maran, T. et al., 2016. Animal umwelten in a changing world. Tartu: University of Tartu Press, available at: <https:// www.researchgate.net/publication/310828174_Animal_Umwelten_in_a_Changing_World_Zoosemiotic_ Perspectives>

Martinelli, D., 2010. A critical companion to zoosemiotics: People, paths, ideas. Dordrecht: Springer, available at: <https://www.researchgate. net/publication/321609704_A_Critical_Companion_to_Zoosemiotics_People_Paths_Ideas>, $<$ https://translate.googleusercontent.com/translate_c?hl=en-US\&sl=en\&tl=ru\&u=https://link.springer. com/content/pdf/bfm:978-90-481-9249-6\%252F1. pdf?error\%3Dcookies_not_supported\%26code\%3Db981c832-5a44=41-cf-7b0d93119-ba29d5b\&usgALkJrhjF08uxgQguqP7sRx6sLQHIUutOgQ>

Mithen, S., 2005. The singing Neanderthals: The origins of music, language, mind, and body. London: Weidenfeld \& Nicholson, available at: <https://www. researchgate.net/publication/41571921_The_singing_Neanderthals_The_origins_of_music_language_ mind_and_body>

Morris, C., 1955 [1946]. Signs, Language, and Behavior. New York: George Braziller.

Olay, C., 2020. Self-interpreting Language Animal: Charles Taylor's Anthropology. In: Kulcsár-Szabó Z., Lénárt T., Simon A., Végső R. (Eds.), Life After Literature. Numanities-Arts and Humanities in Progress, vol 12. Cham, Springer, available at: <https://doi. org/10.1007/978-3-030-33738-4_9>

Peirce, C. S., 2000 [1965-1967]. Izbrannyye filosofskiye proizvedeniya. Per. s angl. K. Golubovich, K. Chukhrukidze, T. Dmitriyeva. Moskwa: Logos. (In Russian). Trans. from Peirce C. S. Collected Papers. Ed. by C. Hartshorne and P. Weiss; Arthur W. Burks. Vol. 1-8. Cambridge-Mass.: The Belknap Press of Harvard University Press, 1965-1967, available at: <https://drive.google. com/file/d/0B3S-kpls80DCOThKZ2VYeEhSakU/view>

Reznikova, Z., 2017. Studying Animal Language Without Translation: An Insight From Ants. Switzerland: Edition
First Publisher: Springer International Publishing, available at: <https://www.researchgate.net/publication/319683236_Studying_Animal_Language_ Without_Translation_An_Insight_From_Ants>

Savage-Rumbaugh, S.. Rumbaugh, D., Fields, W., 2009. Empirical kanzi: The ape language controversy revisited, Skeptic. 15(1), 25-33.

Sebeok, T. A., 1990. Essays in zoosemiotics. Toronto: Victoria College in the University of Toronto.

Seyfarth, R. M., Cheney., D. L., 2018. Edited by Michael L. Platt. The Social Origins of Language, Princeton: Princeton University Press. $x-167$, available at: <https:// doi.org/10.1515/9781400888146-003>

Shabanov, P. D., Lebedev A. A., 2007. Zoosotsial'noye povedeniye krys. [Zoosocial behavior of rats]. Obzory po klinicheskoy farmakologii i lekarstvennoy terapii. [Reviews of clinical pharmacology and drug therapy]. 5(3), 2-79, available at: <https://cyberleninka. ru/article/n/zoosotsialnoe-povedenie-krys/viewer>

Taylor, C., 2016. The Language Animal: The Full Shape of the Human Linguistic Capacity .Cambridge, MA: Harvard University Press, available at: <https://www. researchgate.net/publication/321812983_The_Language_Animal_The_Full_Shape_of_the_Human_Linguistic_Capacity_Cambridge_MA_Londres_Belknap_ Press_of_Harvard_University_Press_352_pp>

Wendler, H., 2020. Philosophical Primatology: Reflections on Theses of Anthropological Difference, the Logic of Anthropomorphism and Anthropodenial, and the SeIf-other Category Mistake Within the Scope of Cognitive Primate Research. Biological Theory 15, 61-82.

Return to front page $\uparrow$ 